\title{
Wuhan Commercial Jockey Credibility Preliminary Analysis System
}

\author{
Cheng YANG ${ }^{1}$, Yi LI ${ }^{1}$ and Bo XIA ${ }^{2}$ \\ ${ }^{1}$ Wuhan Business University, Wuhan, Hubei, China 430056; \\ ${ }^{2}$ Wuhan University of Science and Technology, Wuhan Hubei China 430056
}

Keywords: Wuhan, Horse racing business, Credibility, System.

\begin{abstract}
This article from the perspective of credibility investigate the risk of Wuhan Commercial horse racing faces legal, public, economic, game system, etc., by analyzing the problems of the current commercial horse racing credibility, from the legal, game system, media control and management system, event subject control and other dimensions proposed index system of commercial horse racing credibility evaluation, with a view to the development of relevant laws and policies provide some reference for the development of horse racing in Wuhan business and government and a reference.
\end{abstract}

\section{Introduction}

Eighteen Party government work report made it clear to "deepening administrative reform, building functions science, structural optimization of service-oriented government" and stressed "the administration to be innovative ways to improve the credibility of the government and executive power." Now is the critical stage of social transformation, and improve the government's credibility, has become China's stage to build a beautiful China, building a moderately prosperous society in an important task. Recalling the history of the development of China's commercial horse racing, it is easy to see since the reform and opening up government has never stopped exploring the mainland commercial horse racing pace, however, due to the risk management system is not perfect, the relevant regulatory system is imperfect, for lack of proper understanding of risk events, resulting in a peripheral horse races rampant corruption, fraud is serious, risk management loopholes, commercial horse racing event credibility is non-existent, a direct impact on the local social order, weaken the local government's image. Therefore, to establish business credibility is particularly important horse racing events [1]. Credibility can be understood as the degree of public trust in government. In the commercial horse racing. If the government more to get the public's trust, the more its legitimacy can be recognized, the more stable its development, the development of commercial horse racing should bear social welfare will be more smoothly performed. However, our government during the transition period in the economic credibility emerged hysteresis, Wuhan commercial horse racing also had an impact.

\section{The Next Question the Credibility of Sight of Wuhan Comme rcial Horse Racing}

\section{The Revision System and Legal Risks}

Contestants for cheating, doping horses, Lottery potential problems caused by the proliferation of commercial horse racing are to be solved. As a whole industry wants a good prospect, it needs to coordinate the interests of all parties, but the internal organizational structure of commercial horse racing incomplete development strategy 
is not clear, the relevant provisions and the legal system is not complete, so that the business of horse racing No more development management approach, which will affect the government control over the commercial horse racing [2], reduce the social credibility of horse racing lottery industry is not conducive to the development of commercial horse racing.

\section{The Public Risk}

Ma Cai cognitive masses too narrow, color blind ness public on the Lottery, disclosure and public information in the form of commercial horse racing event and there is no clear standard, resulting in commercial horse racing if contrary to social morality has become a big society public issues, and various media always say diverse and sensitive public opinion wind elusive, if not guided, it is easy to cause the entire horse racing ind ustry image sink.

\section{Economic Risk}

Horse racing industry in the huge market potential to be a huge economic investment, horse racing betting activities required to support high-consumption groups. But the domestic per capita GDP is clearly insufficient to support a huge horse racing ind ustry. Domestic investment in high-income earners is an important factor lottery market development, and currently participating in the lottery consumption of high-income earners less stake and purchase low quantities. Horse racing industry in the development of a huge economic risk.

\section{The Integrity of Horse Racing in Wuhan Business Analysis}

\section{Legal and Regulatory Systems and Risk}

Currently across the country test run business fail because horse racing, mainly because countries have only acquiescence, no legislative support. Internal control, risk assessment is not in place, communication hampered internal oversight confusion these risks in a complex form of cross composite still unresolved, the risk system architecture and organization is not clear. While in 2005, the third meeting of the CPPCC, the CPPCC National Committee members advocate for some issue recommendations "horse race lottery", the Financial following answer is that it is necessary to study the feasibility of horse racing lottery, the same year, the study group set up quiz sports lottery type in Wuhan horse racing lottery group, and a number of domestic and foreign experts to discuss and prepare a study on horse racing lottery, designed to find the right path suited to China's national conditions of release Ma Cai [3]. Wuhan Orient Lucky City also support research team under the State Sports General Administration of Sports Lottery Center under the authority formally established. But now the horse color development, the state did not make the appropriate legislative measures to guarantee the smooth development of horse racing business in China, there is no specific laws and regulations regulating commercial horse racing activities, modern horse racing industry "without just cause" Unable to health lasting hair exhibition.

\section{The Information Disclosure and Public Issues}

Currently racing event indeed to fully open horse owners, horses and jockeys relevant information, before Open weighing, process checks and anti-fraud mechanisms to protect tournament results and timely feedback information and other ways to protect the transparency and timeliness of events, However, contact with the media to be 
strengthened. Few large-scale events have a direct televised, mostly in the form of news reports appeared. Newspapers, books, radio and other media for commercial horse racing lack of proper understanding, more neutral attitude is retained in the network media, to carry out activities for the commercial horse racing is indeed a clear stand for or against the face of the relevant motion. proposal, people have different opinions, it said Ming Ma Cai guidance of public opinion or is this a big risk exists. If horse racing can be carried Wuhan business, then the society of horse racing events will be more intense public controversy. Then it's living environment and risks will be even worse, its influence public opinion risks also goes without saying that public opinion cannot be sensitive to grasp the wind, so that ordinary people can recognize Ma Cai open yet to be concerted efforts of various sectors [4]. Commercial horse racing industry as a new development, we must get to a formal recognition and support of the community, increase the commercial horse racing propaganda, changing people's traditional misconceptions about horse racing business, so that ordinary people know that horse racing is not just a sport, but also to understand Jockey deep cultural connotation of social development and public welfare has a unique contribution to the role. Horse racing lottery is one of the important modern gaming branch, publicity Ma Cai is sponsored by the government social welfare activities of the business, its ultimate purpose is social welfare charity, help more people who need help to better social development.

\section{The Circumstances Racing Mode and Professionals}

Under the present conditions, the Wuhan Jockey only at the primary level of development, although participation in the government's guidance and support, organization and supervision, but still not perfect racing mode, planning and determination of events is not the national financial sector, the National Lottery Center, the agricultural sector, Join local horse racing associations and other relevant institutions. From the current perspective of the development of horse racing events, on horse racing, horse color lack a correct understanding of the market mechanism is not perfect. Currently, only in Wuhan Ma Cai pilot, although Ma Cai still hold over the country, but they are to guess the horse in the form of gifts to attract viewers, these are not simply road racing sports development in China [5]. Currently, scientific and rational set of horse color and planning is the only way, thus promoting the rapid development of China's commercial horse racing industry. The lack of racing professionals also inhibit the development of horse racing industry. Racing industry professionals lack a certain extent, restricted the issuance of Wuhan Jockey Lottery SMG needed to build the platform, not in-depth study on how to establish a development model horse racing business in line with China's national conditions, if only according to the current allocation mechanism welfare lottery and sportsBetting mode, development of commercial horse racing will be very difficult. Despite racing official university degree professionals in recent years gradually develop, however, the number of our existing range of equestrian clubs and talent demand point of view, the number of professionals far short of demand, and most professionals do not just businessdepth study of a particular aspect of horse racing, the lack of academic also inhibit the implementation of commercial horse racing.

\section{The Construction of the Theoretical Study of Wuhan Comme rcial Horse Racing}

Commercial horse racing not only requires a certain level of competition itself, and often participate in events and persons attended the event more extensive marketing 
and media coverage, while the political, economic, cultural and other aspects of the venue profound radiation leading role. Because of wide commercial horse racing event involves many influencing factors, so the face of events risks that need to use SMART principle sources of risk events be identified, in order to reach for maximum security with minimum cost purposes.

Target commercial horse racing event should be scientific and rational. From the time considerations, the risk can be divided into pre-match risk, risk game and after the game when the risk of public opinion before the primary consideration, economic and political risks, financial risks the main consideration race, organization, responsibility, unexpected situations, after the game Event consider the impact and image of the organization and other risks, based on the risk characteristics of the time period so that different portions on response measures should be taken, can enhance risk response targeted objectives [6]. From space, the commercial horse racing event risk management organization can be divided into different levels of departments, organizations progressive layers perform their duties on the Principles tends to flatten, to ensure the flow of information on the lower level, so that the whole the efficient operation of the organization, departments target refinement, unified command, rights and responsibilities, to ensure the successful operation of the division of labor events, to ensure that the commitment to goals and feedback, conducive to the event. Can build credibility atmosphere four steps:

First, the Government, through setting goals, and constantly improve their own management capabilities based on the current situation, the formation of a scientific and reasonable commercial horse racing event schedule, by consolidating the internal infrastructure to build the credibility of the system, and gradually improve the internal business related infrastructure and racing schedule management conditions, to build a good foundation for the credibility of the preparation conditions.

Second, the government needs to race through the method of trial operation, the time to make adjustments based on the risk and deeds case, the horse racing business income applied to the maintenance of social charity undertakings and infrastructure racecourse and other formal channels up, so that the government's achievements You can get the people to believe and identity, so that the government supported the masses, to facilitate future work.

Third, the added crisis management and control mechanisms, in the face of Wuhan development risks and issues facing commercial horse racing industry, in the process of building the credibility of the system, adding the crisis ATC mechanism is very important.Effective management experience to fully draw his country, you can use a shorter time to complete the system, the legal and technical basis for the creation, then combined with mainland China's national conditions, make the necessary innovation, you can avoid detours, to avoid major mistakes. Moreover, since horse racing events still in its infancy, in order to reduce losses caused by the crisis, the approval authority shall state control racing pilot, horse racing industry and state business and management, on the one hand the national crisis control efforts, the country can take advantage of credibility, get more social support, in support of the national economy, to raise more funds, on the other hand, the credibility of the country to build the body, established by the country of a transparent and comprehensive communication mechanisms to monitor, depending on the risk and questions to constantly adjust the business of horse racing system in order to improve the risk prevention capability. 


\section{According to Metrics That Enhance the Credibility of Wuhan Commercial Horse Racing}

\section{Legal System}

The scope of legislation should be comprehensive, covering a wide introduction, details perfect racing law, from a legal perspective to support and regulate horse racing business conduct. Horse racing industry laws and regulations, as our constitution as uniformly formulated and promulgated by the State Council. Judging from the scope of legislation, from the mode of operation of the racecourse to build regulatory system, from horse owners and horses to the contestants should be provided with the appropriate statutory regulations. In the event if there is opportunistic want to help others through inappropriate means or staff to win the game or race driver, in accordance with relevant laws and regulations in this part of the staff treated less serious canceled when tournament results, it does not return the deposit the circumstances are more serious disqualify game, prohibit a fine race, revoke its license. If the circumstances are especially serious in its criminal responsibility in accordance with law.

\section{The Extent of the Internal Control Improvement}

From the organizational structure point of view, we should establish a set of government-led force's internal management systems. But in the present situation, Ma Cai belong among the sports lottery, the development has some limitations. According to the conditions of development, the horse racing event of internal management model should be made: Under the leadership of the State Sports General Administration, the Chinese Equestrian Association is responsible for management and operation of horse racing events, and its supervision, the National Sports Lottery Center is responsible for horse racing betting and guessing, and the division of labor between the two, and cooperation.Promote the development of horse racing lottery; Ministry of Finance is responsible for approving and monitoring. In this model, we need to use SMART to establish a scientific risk assessment system and improve risk identification and analysis capabilities, to take timely and effective measures to reduce the risk of loss development of commercial horse racing.

\section{The Event Management Rigor}

Commercial horse racing schedule requires standardization of horses and contestants strictly controlled, for example, in Hong Kong, horse owners and horses must be registered to participate in the annual event to enter the stadium, when registering foreign horses, horse's name, ancestry, age, sex and Coat color and any recognizable stamp of horses and other information will be detailed records of each horse to go through after a formal mechanism to determine the origin of horses record to qualify participating. In terms jockey jockey access system can be established, before participation game, jockeys and horses receiving drug and weight checks, assessment pound member of the horses and jockeys pounds review, did not meet the requirements for an increase in pounds, in order to achieve a fair, jockeys and horses waiting at the side, the commentary pound member of the audit results announced by the pound in the trial of the horses in the horse ring, inspected the venue and staff greeted the audience and the media after the game's further real events, to ensure fair and equitable. In response to emergencies on the field and health safety issues, logistics departments should be ready to make the appropriate preparations to guide the work of the public relations department of public events should also be in place. 


\section{Ackno wledge ment}

This research was financially supported by the Department of Education in Hubei Provincial 2014 Humanities and Social Science Found ation (NO. 14G492)

\section{Reference}

[1] Yang, HuqingShan, Chen Shaoyan, Zeng spin. Wuhan City Commercial horse racing industry development, manufacture and Route [J]. Shanghai Institute of Physical Education. 2011 (05)

[2] Zhang Qing credibility of sports organizations Anomie Sociological Perspective [J] Xi'an Institute of Physical Education 2010, 27 (6):... 674-677

[3] Liang Bo, Sociological Analysis and Countermeasures Min learning events of football produced a crisis of confidence [J] Xi'an Institute of Physical Education 2013,30 (6): 677-680

[4] Nil level of Sports Lottery Social Credit Research [J] Xi'an Institute of Physical Education, 2012, 29 (2): 150-172

[5] Wang Kai, Zhang Lin sports market-oriented operation mechanism in the loss of intangible assets and avoid build [J] sports and science, 2013, 34 (4):68-73 